\title{
Hormone Therapy and Factors Affecting Fertility of Women Under 50-Year-Old with Breast Cancer
}

This article was published in the following Dove Press journal:

Breast Cancer: Targets and Therapy

\author{
Mehdi Moradinazar ${ }^{\prime}$ \\ Behjat Marzbani ${ }^{2}$ \\ Karoon Shahebrahimi ${ }^{3}$ \\ Sara Shahabadi ${ }^{2}$ \\ Behnaz Marzbani ${ }^{4}$ \\ Zeinab Moradinazar ${ }^{5}$
}

'Research Center for Environmental Determinants of Health, School of Public Health, Kermanshah University of

Medical Sciences, Kermanshah, Iran;

${ }^{2}$ Health Education and Promotion Group,

Vice Chancellor for Health Affairs,

Kermanshah University of Medical

Sciences, Kermanshah, Iran; ${ }^{3}$ Department of Internal Medicine, Imam Reza Hospital,

Kermanshah University of Medical

Sciences, Kermanshah, Iran; ${ }^{4}$ Health

Education and Promotion Group, Health

Network of Kermanshah, Vice

Chancellor for Health Affairs,

Kermanshah University of Medical

Sciences, Kermanshah, Iran; ${ }^{5}$ School of

Health, Kermanshah University of

Medical Sciences, Kermanshah, Iran
Correspondence: Behjat Marzbani Health Education and Promotion Group, Vice Chancellor for Health Affairs, Kermanshah University of Medical

Sciences, Kermanshah, Iran

Tel +98 9183575503

Email marzbanibehjat@gmail.com
Background: Although the use of contraceptive hormones is a risk factor for development of breast cancer, level of risk is unknown; thus the current research was conducted to investigate the effect of factors related to fertility and hormone use on risk of breast cancer in women aged under 50 years old in the west of Iran.

Methods: In this case-control study, all incidence cases of breast cancer aged between 25-49 years old $(n=212)$ were selected. Twice as many as the case group, the individuals referred to other outpatient sections of the same hospital at the time of study and up to 2 years after the follow-up not diagnosed with breast or other cancers were selected as a control group. The data were collected using healthy fertility program and middle-aged periodical care forms developed by Iran's Ministry of Health (MOH).

Results: After controlling for confounding variables, history of hormonal use for contraception $(\mathrm{OR}=2.02,95 \% \mathrm{CI}=1.2-3.3)$ and hormone therapies $(\mathrm{OR}=1.9,95 \% \mathrm{CI}=1.2-3.04)$ were identified as factors increasing the risk of breast cancer. Dose-response relationships between breast cancer and the use of hormones for contraception and hormone therapy indicated that these factors increased the risk of breast cancer. The risk was found to be higher in women who had been under hormone therapy for more than 120 months. With an increase in the age of the first menstruation, risk of breast cancer increased linearly, but with an increase in the age of the first pregnancy, risk of breast cancer increased exponentially. After 20 years of age, the risk increased with a steeper slope.

Conclusion: Considering the effect of hormone therapy and fertility factors on breast cancer and changeability of listed risk factors, the researchers suggest planning for sensitizing, increasing the awareness, and educating women and professionals regarding the influence of fertility and hormonal factors including pregnancy at lower ages, minimizing the use of hormones for contraception, and hormone therapy.

Keywords: fertility, contraception hormones, hormone therapy, breast cancer

\section{Introduction}

Cancer is one of the most significant public health issues throughout the world. ${ }^{1}$ As predicted by the World Health Organization (WHO), the death rate from cancer will increase to 24 million people by 2035 . Breast cancer is the leading cause of cancer in women throughout the world ${ }^{2}$ and is one of the most commonly known causes of deaths by cancer among women in developed and developing countries. ${ }^{3,7}$ In recent decades, its prevalence has been rapidly increased in many developing countries ${ }^{8}$ so thatits incidence is reported as 27 per 100,000 people in the Eastern Mediterranean Region. ${ }^{9}$ According to $\mathrm{WHO}$, the incidence rate of breast cancer rises between $1.8-2 \%$ per annum. ${ }^{10,11}$ Thus, about a $26 \%$ increase in the current rate of breast cancer can be expected until 2020 , mainly in developing countries. ${ }^{5}$ 
In Iran, the epidemiological pattern of breast cancer is similar to that of Eastern Mediterranean and other developing countries. ${ }^{5}$ With respect to the change in risk and demographic pattern of cancer in Iran, its incidence has significantly increased over the recent years. ${ }^{12,13}$ According to the report published by WHO on recorded cancer data, with an age-standardized incidence rate of $28.25 \%$, breast cancer is the most common type of cancer among Persian women. ${ }^{14}$ The incidence of breast cancer in Persian women is higher than developed countries, and its mean age range is less than the global rate. Results of studies conducted in Iran showed that the mean age range of affected women is between 40-50 years old, ${ }^{15}$ which is about $10-15$ years less than the global average. ${ }^{16}$ Findings of research performed in Iran suggested that $23 \%$ of cases with breast cancer were under 40 years old and $70 \%$ of them were diagnosed at an advanced level of the cancer, ${ }^{17}$ while early diagnosis of this disease, especially in the early stages of the cancer, is an important factor in reducing its death rate. ${ }^{18}$

According to an announcement of the American Cancer Society (ACS), there are several risk factors for breast cancer. ${ }^{19}$ As reported in a number of studies, the most common risk factors during a women's fertility period are early age of menstruation, late menopause onset, pregnancy at older ages and use of hormones. ${ }^{20}$ To prevent development of breast cancer, it is important to study its risk factors as well as epidemiology. ${ }^{21}$ Due to the high prevalence of intake of contraceptive hormones, they are important for women's general health. In the United States, more than 45 million American women aged between 15-44 years old have had a history of using contraceptive hormones, and 10.7 million people are currently using them. ${ }^{22}$ The International Agency for Research on Cancer (IARC, 2005) reported the use of contraceptive hormones by $7.3 \%$ of women, on average; in the meantime, it was reported to be used by 15.7 and $5.8 \%$ of women, respectively, in developed and developing countries. ${ }^{23}$

Although the use of contraceptive hormones is a risk factor for development of breast cancer, the level of risk is unknown, and this is a controversial issue in this field of study. ${ }^{21}$ Many researchers studied the effect of hormonal use and related factors, but there are still contradictory results regarding the relationship between these factors and incidence of breast cancer. Based on meta-analysis results of a case-control study by Kahlenborn et al, ${ }^{24}$ the use of oral contraceptive hormones increased the risk of breast cancer. Furthermore, depending on the type of used oral contraceptives (oral, injectable, or implant), risk of breast cancer would be different and uncertain. Research on a small group of women who had used implants showed an increased risk of breast cancer. ${ }^{25}$ In another cohort study conducted in Thailand, Poosari et $\mathrm{al}^{26} \mathrm{did}$ not find a relationship between the use of contraceptive hormones and the incidence of breast cancer. Besides, the difference between the incidence of this cancer in different regions and the variety and extent of the factors influencing the incidence of breast cancer highlights the need for studying different regions to clarify the role of fertilityrelated factors, the use of hormones to prevent pregnancy, hormone therapy and the risk of breast cancer. Thus, the current research was conducted to investigate the effect of fertility-related factors and use of hormones on the risk of breast cancer in women living in the west of Iran.

\section{Materials and Methods Study Population}

This case-control study was conducted on 620 women (212 cases with breast cancer and 408 healthy women as a control group) in the west of Iran (Kermanshah province) in 2017. In the first phase of the study in 2015, all the women were aged between 25-49 years old $(n=212)$, diagnosed with breast cancer according to positive pathology test result obtained between 2013-2015, and referred to radiotherapy, oncology, and chemotherapy clinics of the cancer diagnosis referral center in the west of Iran (Imam Reza Referral Hospital) were selected as a sample group. As shown in Figure 1, 25 cases who did not meet the inclusion criteria were excluded from the study. Excluded subjects were one Iraqi woman excluded because of ethnic issues and language problems in communication (4\%), two men (8\%), 13 subjects who were not in a good mental condition for an interview because of their disease (52\%), and another nine subjects were excluded because of their unwillingness to participate in the study (36\%). The women referred to other departments of the same hospital (sonography, ophthalmology, gynecology, and ENT) were selected as a control group through the available sampling method. Per each case in the case group, two subjects with no history of breast cancer or any other disease or cancer were included in the control group.

In the second phase of the study, all the subjects of the control group were followed up for 2 years to minimize error and reduce the risk of breast cancer in the control group. During this period, 28 subjects were excluded from the control group, including six women $(21.4 \%)$ because of being diagnosed with other cancers, nine women 


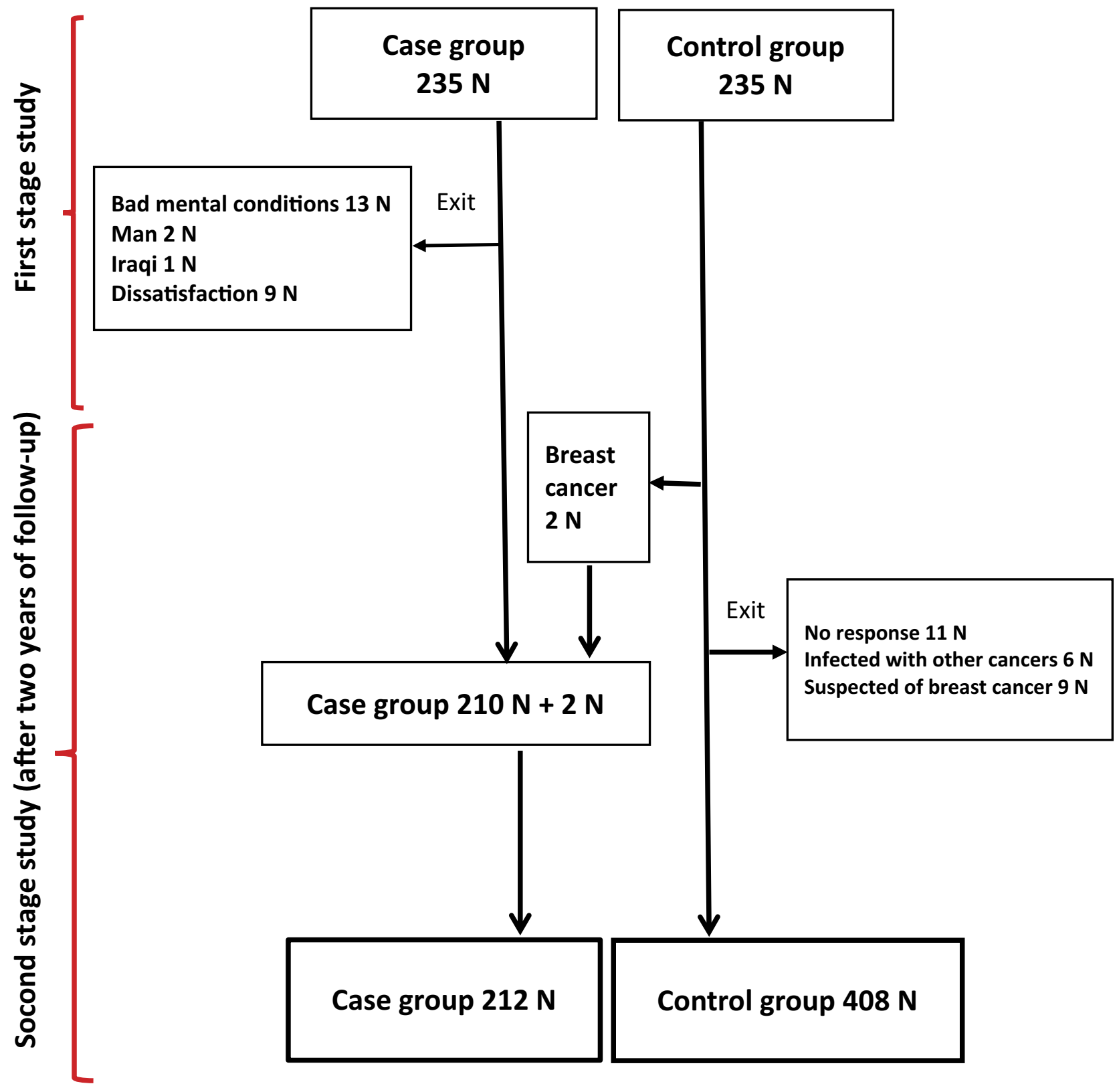

Figure I Chart of the research implementation process.

(32.2\%) because of having clinical symptoms of breast cancer, 11 women $(39.2 \%)$ because of not being available, and two women $(7.1 \%)$ because of being diagnosed with breast cancer (positive pathology results). The last two subjects were included in the case group (Figure 1).

\section{Data Collection and Research Variables}

Data collection was performed through in-person interview and examination of hospital records. In addition to demographic questions and anthropometric survey (measurement of weight, height and body mass index), middle-aged periodical care form developed by Iran's Ministry of Health $(\mathrm{MOH})$ was also used to evaluate physical activity and dietary patterns of the subjects. ${ }^{27}$ To assess the use of hormones for contraception, a 22-item healthy fertility program form was employed for the use of contraceptive pills (HD, LD, Triphasic, Levonorgestrel and Lynestrenol), injection (once a month and once every 3 months), Norplant contraceptive implants, and Intrauterine Device (IUD). The hormones were categorized into fourgroups: oral contraceptives, injectable contraceptives, as well as capsules implanted in the arm and uterus (Table 1). 
Table I Classification and Type of Hormone

\begin{tabular}{|l|l|}
\hline \multirow{5}{*}{ Oral contraceptives } & Contraceptive LD \\
\cline { 2 - 2 } & Contraceptive HD \\
\cline { 2 - 2 } & Contraceptive Tri phasic \\
\cline { 2 - 2 } & Levonorgestrel \\
\cline { 2 - 2 } & Lynestrenol \\
\hline \multirow{2}{*}{ Injectable ampoule } & Cyclophoma \\
\cline { 2 - 2 } & Depogesteron (DMPA) \\
\hline Implant capsule in the arm & Norplant \\
\hline Inside the uterus & IUD \\
\hline
\end{tabular}

\section{Nutritional Status}

The middle-aged integrated healthcare form developed by Iran's Ministry of Health was used to assess dietary patterns of the subjects. This questionnaire is used routinely by the Iran's Ministry of Health to assess individuals' diet consisting of two sections of Favorable and Unfavorable Nutritional Statuses. Favorable Nutritional Status includes consumption of fruits, vegetables, and dairy products daily; no consumption of salt, solid, or semi-solid oil, fast food, and soda, industrial juices, fried foods, low-value sweets, and snacks on a usual basis or once a month. Unfavorable Nutritional Status includes consumption of fruits, vegetables, and dairy products on a weekly or monthly basis; consumption of salt, solid or semisolid oil, fast food, soda, industrial juices, fried foods, lowvalue sweets, and snacks more than once a month. ${ }^{28}$

\section{Physical Activity Status}

Regarding physical activity status, subjects are categorized into three statuses of activity: passive individuals, and those with favorable and unfavorable status of activity. Passive subjects are individuals who have no physical activity. Unfavorable Activity: light activities that do not cause sweating or do not increase the heart beat (such as low-pace hiking, light exercise, daily activities or any kind of light physical activity), less than 150 minutes of regular exercise per week (exercises causing low sweating such as brisk walking, slow swimming, slow cycling, aerobic, jumping rope, treadmill workout, spin bike workout, etc.), or less than 75 minutes of heavy exercise per week (exercises causing excessive sweating and increasing the heart beat such as running, body building, mountain climbing, fast swimming, or any other heavy activity). Favorable Activity: more than 150 minutes of regular exercise per week or more than 75 minutes of heavy exercise per week.

\section{Ethical Considerations}

From all participants, verbal informed consent was obtained. The questionnaires were filled-in after obtaining the approval of the Ethics Committee at Kermanshah University of Medical Sciences about verbal informed consent and other parts of proposal (IR.KUMS.RES.1398.672). The Ethics Committee was fully aware of the verbal informed consent process and we justified that there was no harm from our research for participants. In addition, most of our data gathering has been done via telephone contact.

\section{Data Analysis}

Collected data were analyzed using Stata software (V.14.1) by calculating central and dispersion indices (average, mean, and standard deviation). To study the relationship between variables, the univariate and multivariate Frequency Match Logistic Regression model and Odds Ratio were used with $95 \%$ confidence interval at a significance level of 0.05 . Fractional polynomials were used to quantify the effects of hormone therapy and factors influencing fertility on odds of breast cancer. Fractional polynomials are an alternative to regular polynomials providing flexible parameterization for continuous variables. In this method, first, the effects of demographic variables and body mass index (BMI) on breast cancer risk were controlled. Then, the effect of hormone therapy models was assessed.

\section{Results}

A total of 620 women aged between 25-49 years old (212 cases with breast cancer and 408 healthy women as a control group) were included in this research. The mean age of the subjects was equal to $41.5 \pm 6.2$ and $39.5 \pm 7.1$ years old, respectively, in the case and the control groups. The mean age of the first menstruation of the subjects was equal to 13.3 \pm 1.5 and $13.7 \pm 1.6$ years old, respectively, in the case and the control groups $(P<0.05)$. The mean age of the subjects at first marriage was equal to $20.6 \pm 5.1$ and $19.0 \pm 4.5$ years old, respectively, in the case and the control groups $(P<0.05)$. The mean age of the subjects at first pregnancy leading to a live birth was equal to $23.2 \pm 5.5$ and $21.4 \pm 4.9$ years old, respectively, in the case and the control groups $(p<0.05)$.

Unfavorable nutritional status was observed in the dietary pattern of $94.3 \%(n=200)$ and $96.4 \%(n=598)$ of women, respectively in the case and control groups. In the control group, $81.86 \%(\mathrm{n}=334)$ of women were married; $13.2 \%$ $(n=54)$ of them were single, and $4.9 \%(n=20)$ of them were divorced/widowed. In the case and control groups, $13.2 \%$ and $19.11 \%$ of women were illiterate, respectively (Table 2). 
Table 2 Univariate and Multivariate Logistic Regression for Risk Factors of Breast Cancer

\begin{tabular}{|c|c|c|c|c|c|}
\hline \multicolumn{3}{|l|}{ Variable } & \multirow{2}{*}{$\begin{array}{l}\begin{array}{l}\text { Case/Control } \\
(\%)\end{array} \\
14 / 69(16.87) \\
70 / 14,632.41) \\
128 / 193(39.88)\end{array}$} & \multirow{2}{*}{$\begin{array}{l}\begin{array}{l}\text { Crude OR } \\
(95 \% \text { CI) }\end{array} \\
\text { Reference } \\
2.36(1.2-4.48) \\
3.26(1.7-6.05)\end{array}$} & \multirow{2}{*}{$\begin{array}{l}\begin{array}{l}\text { Adjusted OR } \\
\text { (95\% Cl) }\end{array} \\
\text { Reference } \\
2.5(1.3-5.1) \\
3.6(1.9-7.1)\end{array}$} \\
\hline $\begin{array}{l}\text { Demographic } \\
\text { information }\end{array}$ & Age group & $\begin{array}{l}\leq 30 \\
31-40 \\
4 I-49\end{array}$ & & & \\
\hline & Level of education & $\begin{array}{l}\text { Illiterate } \\
\leq 9 \\
10-12 \\
\geq 13\end{array}$ & $\begin{array}{l}28 / 78(26.4) \\
107 / 167(39.0) \\
41 / 79(34.2) \\
36 / 84(30.0)\end{array}$ & $\begin{array}{l}\text { Reference } \\
1.7(1.0,2.9) \\
1.4(0.8,2.5) \\
1.9(0.6,2.1)\end{array}$ & \\
\hline & Location & $\begin{array}{l}\text { Urban } \\
\text { Rural }\end{array}$ & $\begin{array}{l}170 / 349(32.8) \\
42 / 59(7 \mid .2)\end{array}$ & $\begin{array}{l}\text { Reference } \\
1.4(0.9-2.2)\end{array}$ & \\
\hline & Marital status & $\begin{array}{l}\text { Married } \\
\text { Single } \\
\text { Divorced/widowed }\end{array}$ & $\begin{array}{l}176 / 334(34.5) \\
27 / 54(33.3) \\
9 / 20(31.0)\end{array}$ & $\begin{array}{l}\text { Reference } \\
0.9(0.5-1.5) \\
0.8(0.3-1.9)\end{array}$ & \\
\hline \multirow[t]{5}{*}{ Lifestyle status } & BMI $\left(\mathrm{kg} / \mathrm{m}^{2}\right)$ & $\begin{array}{l}<24.9 \\
24.9-29.9 \\
29.9-34.9 \\
>34.9\end{array}$ & $\begin{array}{l}63 / 140(31.0) \\
99 / 166(37.4) \\
35 / 84(29.4) \\
15 / 18(45.5)\end{array}$ & $\begin{array}{l}\text { Reference } \\
1.3(0.8-1.9) \\
0.9(0.5-1.5) \\
1.8(0.8-3.9)\end{array}$ & \\
\hline & Nutrition & $\begin{array}{l}\text { Favorable } \\
\text { Unfavorable }\end{array}$ & $\begin{array}{l}12 / 10(54.5) \\
200 / 398(33.4)\end{array}$ & $\begin{array}{l}\text { Reference } \\
2.38(1.01-5.6)\end{array}$ & \\
\hline & Physical activity & $\begin{array}{l}\text { Favorable } \\
\text { Unfavorable } \\
\text { No }\end{array}$ & $\begin{array}{l}14 / 40(26.0) \\
75 / 170(30.6) \\
123 / 198(38.3)\end{array}$ & $\begin{array}{l}\text { Reference } \\
1.2(0.6-2.4) \\
1.7(0.9-3.3)\end{array}$ & \\
\hline & Smoking & $\begin{array}{l}\text { No } \\
\text { Yes }\end{array}$ & $\begin{array}{l}210 / 407(34.0) \\
2 / 1(66.7)\end{array}$ & $\begin{array}{l}\text { Reference } \\
3.8(0.3-42.9)\end{array}$ & \\
\hline & Contact with a smoker & $\begin{array}{l}\text { No } \\
\text { Yes }\end{array}$ & $\begin{array}{l}|49 / 3| 7(32.0) \\
63 / 9 \mid(4 \mid .0)\end{array}$ & $\begin{array}{l}\text { Reference } \\
1.4 \mathrm{I}(1.0 \mathrm{I}-2.1)\end{array}$ & \\
\hline \multirow[t]{5}{*}{$\begin{array}{l}\text { Status of factors } \\
\text { affecting fertility }\end{array}$} & Age of the first menstruation & $\begin{array}{l}\text { Late menstruation } \\
(\geq 14) \\
\text { Normal age }(12-13) \\
\text { Early menstruation } \\
(\leq 12)\end{array}$ & $\begin{array}{l}95 / 224(30.0) \\
100 / 160(38.5) \\
17 / 24(41.5)\end{array}$ & $\begin{array}{l}\text { Reference } \\
1.4(1.04-2.08) \\
1.6(0.8-3.2)\end{array}$ & $\begin{array}{l}\text { Reference } \\
1.4(1.03-2.1) \\
1.6(0.8-3.4)\end{array}$ \\
\hline & Age at the first marriage & $\begin{array}{l}\leq 20 \\
21-30 \\
\geq 31 \\
\text { Non-married }\end{array}$ & $\begin{array}{l}107 / 235(31.3) \\
64 / 108(37.2) \\
14 / 11(56.0) \\
27 / 54(33.3)\end{array}$ & $\begin{array}{l}\text { Reference } \\
1.3(0.8-1.9) \\
2.7(1.2-6.3) \\
1.09(0.6-1.83)\end{array}$ & \\
\hline & $\begin{array}{l}\text { Age at the first pregnancy leading } \\
\text { to a live birth }\end{array}$ & $\begin{array}{l}<20 \\
21-30 \\
\geq 31 \\
\text { Non-pregnancy }\end{array}$ & $\begin{array}{l}72 / 170(29.8) \\
82 / 146(36.0) \\
24 / 14(63.1) \\
34 / 78(30.4)\end{array}$ & $\begin{array}{l}\text { Reference } \\
1.3(0.9-1.9) \\
4.07(1.9-8.2) \\
1.02(0.6-1.6)\end{array}$ & $\begin{array}{l}\text { Reference } \\
1.4(0.9-2.1) \\
4.5(2.06-9.8) \\
2.00(1.03-3.8)\end{array}$ \\
\hline & Number of pregnancies & $\begin{array}{l}I-2 \\
3-4 \\
\geq 5 \\
\text { Infertility/single }\end{array}$ & $\begin{array}{l}100 / 180(36.0) \\
69 / 114(38.0) \\
9 / 36(20.0) \\
34 / 78(30.4)\end{array}$ & $\begin{array}{l}\text { Reference } \\
1.08(0.7-1.6) \\
0.45(0.2-0.9) \\
0.7(0.4-1.2)\end{array}$ & \\
\hline & Lactation history & $\begin{array}{l}\text { Yes } \\
\text { No }\end{array}$ & $\begin{array}{l}170 / 320(34.7) \\
42 / 88(32.3)\end{array}$ & $\begin{array}{l}\text { Reference } \\
0.8(0.5-1.3)\end{array}$ & \\
\hline
\end{tabular}

(Continued) 
Table 2 (Continued).

\begin{tabular}{|c|c|c|c|c|c|}
\hline \multicolumn{3}{|l|}{ Variable } & \multirow{2}{*}{$\begin{array}{l}\begin{array}{l}\text { Case/Control } \\
(\%)\end{array} \\
41 / 89(31.5) \\
36 / 70(34.0) \\
87 / 128(40.5) \\
48 / 121(28.4)\end{array}$} & \multirow{2}{*}{$\begin{array}{l}\begin{array}{l}\text { Crude OR } \\
(95 \% \text { Cl) }\end{array} \\
\text { Reference } \\
\text { I.I (0.6-I.9) } \\
1.4(0.9-2.3) \\
0.8(0.5-1.4)\end{array}$} & \multirow{2}{*}{$\begin{array}{l}\text { Adjusted OR } \\
(95 \% \mathrm{Cl})\end{array}$} \\
\hline & Lactation duration (month) & $\begin{array}{l}\text { No } \\
\mathrm{I}-24 \\
25-60 \\
\geq 6 \mathrm{I}\end{array}$ & & & \\
\hline & Abortion history & $\begin{array}{l}\text { No } \\
\text { Yes }\end{array}$ & $\begin{array}{l}148 / 309(32.4) \\
64 / 99(39.3)\end{array}$ & $\begin{array}{l}\text { Reference } \\
1.3(0.9-1.9)\end{array}$ & \\
\hline \multirow[t]{2}{*}{ Hormone intake status } & $\begin{array}{l}\text { Use of hormones for } \\
\text { contraception }\end{array}$ & $\begin{array}{l}\text { No } \\
\text { Yes }\end{array}$ & $\begin{array}{l}61 / 143(30.0) \\
15 \mid / 265(36.3)\end{array}$ & $\begin{array}{l}\text { Reference } \\
1.3(0.9-1.8)\end{array}$ & $\begin{array}{l}\text { Reference } \\
2.02(1.2-3.3)\end{array}$ \\
\hline & Hormone therapy* & $\begin{array}{l}\text { No } \\
\text { Yes }\end{array}$ & $\begin{array}{l}163 / 350(32.0) \\
49 / 58(46.0)\end{array}$ & $\begin{array}{l}\text { Reference } \\
1.8(1.1-2.7)\end{array}$ & $\begin{array}{l}\text { Reference } \\
1.9(1.2-3.04)\end{array}$ \\
\hline $\begin{array}{l}\text { Family history of breast } \\
\text { cancer }\end{array}$ & $\begin{array}{l}\text { A positive family history of breast } \\
\text { cancer }\end{array}$ & $\begin{array}{l}\text { No } \\
\text { First } \\
\text { Second }\end{array}$ & $\begin{array}{l}|8| / 378(32.4) \\
|3 / 1|(54.2) \\
18 / 19(48.6)\end{array}$ & $\begin{array}{l}\text { Reference } \\
2.4(1.08-5.6) \\
1.9(1.01-3.8)\end{array}$ & $\begin{array}{l}\text { Reference } \\
3.01 \text { (1.2-7.2) } \\
2.3(1.1-4.8)\end{array}$ \\
\hline $\begin{array}{l}\text { The state of radiation } \\
\text { therapy }\end{array}$ & $\begin{array}{l}\text { History of radiation therapy on } \\
\text { the chest }\end{array}$ & $\begin{array}{l}\text { No } \\
\text { One time } \\
\text { Two and more }\end{array}$ & $\begin{array}{l}168 / 338(33.2) \\
22 / 43(34.0) \\
22 / 27(45.1)\end{array}$ & $\begin{array}{l}\text { Reference } \\
\mathrm{I} .02(0.5-\mathrm{I} .7) \\
\mathrm{I} .63(0.9-2.9)\end{array}$ & \\
\hline
\end{tabular}

Notes: *Infertility, abortion, menopause, bleeding, ovarian cyst; Goodness of fit model. Sensitivity=62.7; Specificity=87.5; Accuracy=79.03.

Risk for breast cancer increased with age so that women aged between 31-40 years old were 2.5 (95\% $\mathrm{CI}=1.3-5.1)$ times more likely to be diagnosed with breast cancer than those who were 30 years old or less. Women aged between 41-49 years old developed breast cancer 3.6 (95\% CI $=1.9-7.1)$ times more than those who were 30 years old or younger. Higher level of education increased the risk of breast cancer so that the OR was $1.7(95 \%$ $\mathrm{CI}=1.2-9)$ times more in women with elementary or junior high school levels of education than illiterate women, and those with a secondary level of education (high school) were 1.9-times more at risk of developing breast cancer $(\mathrm{OR}=1.9,95 \% \mathrm{CI}=0.6-2.1)$ than illiterate women.

In general, univariate and multivariate logistical regression showed no relationship between developing breast cancer and level of education, place of living, marital status, BMI, nutritional status, physical activity, smoking, contact with smoker, age of the first marriage, number of deliveries, history of breastfeeding, duration of breastfeeding, history of abortion, or history of chest radiotherapy. But, univariate logistic regression showed a significant relationship between developing breast cancer and marital status, contact with a smoker, and age of the first marriage, which was not significant at multivariate logistic regression level (Table 2).

Results showed that those with early onset of menstruation (12-13 years old) compared to late onset of menstruation ( $\geq 14$ years old), and those aged more than 30 years old at the first pregnancy leading to a live birth compared to women under 20 years old were at greater risk of developing breast cancer $(\mathrm{OR}=4.5,95 \%$ $\mathrm{CI}=2.06-9.8 ; \mathrm{OR}=1.4,95 \% \mathrm{CI}=1.03-2.1)$. Women with a history of using contraceptive hormones $(\mathrm{OR}=2.02$, 95\% CI=1.2-3.3), hormone therapy (for treatment of infertility, abortion, menopause, uterus bleeding, and ovarian cyst) $(\mathrm{OR}=1.9,95 \% \mathrm{CI}=1.2-3.04)$, and positive family histories compared to those with a negative family history of breast cancer in first-degree relatives were at increased risk of developing breast cancer $(\mathrm{OR}=3.01$, 95\% CI=1.2-7.2) (Table 2).

After controlling the effect of other confounders, a dose-response relationship was found between the incidence of breast cancer and use of hormones; i.e. the use of hormones for contraception and hormone therapy increased the risk of developing breast cancer. This relationship was stronger in women who were using these hormones for more than 120 months. Dose-response relationship indicated the roles of age at onset of menstruation and the first pregnancy leading to a live birth (in years) in the risk for developing breast cancer. So that, with an increase in the age of the first menstruation, the risk of breast cancer increased linearly, but with the increase in the age of the first pregnancy, risk of breast cancer 
increased exponentially. After 20 years of age, risk increased with a steeper slope (Figure 2).

\section{Discussion}

Previous studies emphasized that age is the most important and challenging risk factor for breast cancer epidemiology. That is, as age increases, risk for developing breast cancer increases as well. ${ }^{20} \sim$ The findings of the current study also showed a direct and significant relationship between age and risk for developing breast cancer. However, with regard to contradictory results reported in the literature about its prognosis in young women ${ }^{29,30}$ and early diagnosis of the cancer, which is of utmost significance in treatment, ${ }^{31}$ it seems that performing screening procedures at an early age is more productive and efficient; which should be taken into consideration by the healthcare providers.
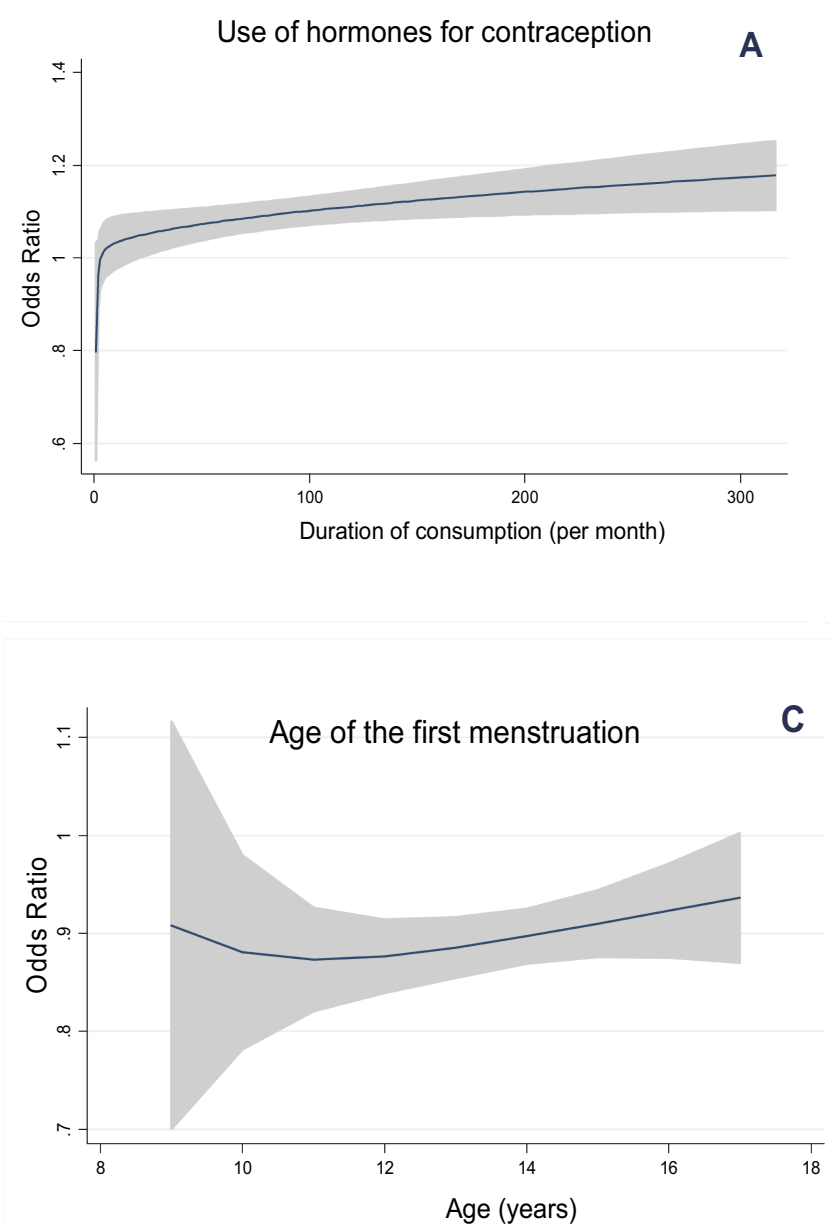

Univariate logistic regression analysis showed a statistically significant relationship between the risk for developing breast cancer and level of education; i.e. the higher the education level, the greater the risk for developing breast cancer. However, at a multivariate level, there was no such relationship after removing the confounders. These findings were in line with some previous studies. ${ }^{32,34}$ However, Das et $\mathrm{al}^{35}$ reported education level as a protective factor in India, maybe because of the effect of confounders such as favorable socioeconomic status, that indirectly influenced risk for developing breast cancer in people with a high education level. This variable was not considered in the current research.

The current research findings showed a significant relationship between the risk for developing breast cancer and place of living while, based on previous studies, the risk of being affected by a disease in urban and rural areas may be

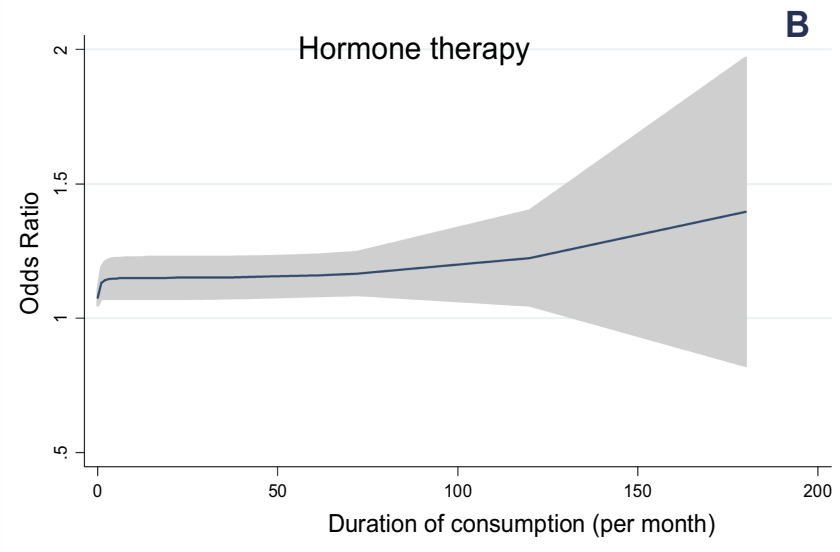

Figure 2 Dose-response relationship for (A) Use of hormones for contraception, (B) Hormone therapy, (C) Age of the first menstruation, and (D) Age at the first pregnancy leading to a live birth after controlling of age, education level, place of living, marital status, smoking, number of deliveries, duration of breastfeeding, nutritional status, and family history of breast cancer. 
due to differences in other environmental factors, including dietary patterns and lifestyles. ${ }^{36}$ Galukande et $\mathrm{al}^{37}$ concluded that there is no difference in the risk for developing breast cancer between rural and urban areas.

Multivariate logistic regression analysis of marital status showed no significant relationship in this regard. Yankaskas et al conducted research in the United States and reported that single people are at greater risk of developing breast cancer than married people. ${ }^{15,38,39}$ To sum up, it seems that marital status, including being divorced and widowed had a low effect on increasing risk for developing breast cancer and its protective influence results from the age of the first delivery leading to a live birth. Thus, late marriage leads to a delay in the first pregnancy and delivery. On the other hand, single women less frequently visit a gynecologist, resulting in late diagnosis and treatment of the disease in these patients. ${ }^{40}$ This issue is of great importance in our country, requiring further investigation.

BMI is one of the most important risk factors for development of breast cancer. In the current study, this variable showed no significant relationship with incidence of breast cancer. Our results are consistent with those reported in the study by Alim et al. ${ }^{41}$ Galukande et $\mathrm{al}^{37}$ found an indirect relationship between BMI and risk for developing breast cancer; however, it was not statistically significant. Such an apparently contradictory relationship could be due to weight loss in the case group in the prediagnosis period. Many studies have suggested that obesity and high BMI are associated with the risk for breast cancer, attributing to release of estrogen from fat cells. $^{42,43}$ This means that, after adolescence, women with higher BMI are at greater risk for developing breast cancer. Thus, maintaining weight in normal range is important in preventing breast cancer. ${ }^{44}$

In this study, first, favorable nutritional status was introduced as a protective factor against developing breast cancer in the univariate regression model. However, after its inclusion in the multivariate regression model and removing the confounders, favorable nutrition was not found to be a significant variable so it was removed. Despite this, in a review carried out by Hajifoghaha et $\mathrm{al}^{45}$ nutritional behavior was effective in developing breast cancer so far that modification of dietary pattern reduced the incidence rate of this disease.

Previous studies introduced physical activity as a factor preventing breast cancer. $^{46,47}$ Furthermore, results of a meta-analysis performed by Pizot et $\mathrm{al}^{48}$ proved that the risk of developing breast cancer was $9 \%$ less in women who had at least 150 minutes of heavy physical activity per week than passive women. Unlike previous studies, in the current research, no significant relationship was obtained for this variable.

The findings of the present study suggested that smoking and being in contact with smokers did not have a significant relationship with risk for developing breast cancer.

Results of a meta-analysis conducted in 2012 showed that early age of the first menstruation increases the risk of breast cancer. ${ }^{49}$ Jafarinia et $\mathrm{al}^{50}$ reported similar results as well. Given the dose-response curve, the risk of developing breast cancer reduced with an increase in the first menstruation age. Early menstruation (under 12 years old) showed a significant relationship with risk for developing breast cancer. On the contrary, menstruation at higher ages acted as a protective factor against risk for developing breast cancer. ${ }^{51}$

It was confirmed that having 30 years of age at the first pregnancy leading to a live birth is a risk factor for development of breast cancer. Different researchers referred to it as a risk factor which can be prevented by intervention. Kamash et $\mathrm{al}^{52}{ }^{52}$ Das et $\mathrm{al}^{35}$ and Galukande et $\mathrm{al}^{37}$ introduced first pregnancy at an early age as a protective factor. ${ }^{53}$ Findings of the current research indicated that, having 30 years of age at the first pregnancy leading to a live birth was the most potent and significant risk factor for breast cancer. Hormonal secretion during pregnancy has dual effects on breast tissue ${ }^{54}$ so that it reduces the risk for developing breast cancer by making further differentiation in mammary epithelial cells. ${ }^{55}$ However, it increases the risk for breast cancer by targeting proliferation of hidden tumor cells. With accumulation of breasts' epithelial cells during the fertility period, when no delivery occurs, maturation of these cells remains incomplete and, if the first pregnancy occurs after 30 years of age, it can increase sensitivity of these cells to simulative effects of growth-promoting hormones leading to their malignancy. ${ }^{56}$ Considering that, in recent years, the age of marriage has risen dramatically among Iranian women, subsequently leading to an increase in the age of the first pregnancy; the researchers suggest conduction of extensive studies in this regard. Furthermore, national policymakers are required to provide better economic, social, and cultural conditions for timely marriage of young people.

Galukande et $\mathrm{al}^{37}$ reported that a history of breastfeeding reduces the chance of developing breast cancer. However, herein, no statistically significant relationship was found for this variable. 
There was no significant relationship between the duration of breastfeeding and risk for developing breast cancer, which was consistent with findings of some other studies. ${ }^{53,57}$ Harrison et $\mathrm{al}^{58}$ concluded that the risk for developing breast cancer decreased with increased duration of breastfeeding.

Some researchers confirmed a carcinogenesis effect of contraceptive hormones, which is consistent with the results of this study. However, some other researchers rejected their significant effect on increased risk for developing breast cancer; ${ }^{59,60}$ e.g. a cohort study conducted by Poosari et $\mathrm{al}^{26}$ in Thailand. Considering that, in this research, it was impossible to separately study different contraceptive methods and their compounds as well as age at onset of their consumption, it is suggested to conduct more extensive and diverse studies on this area of research to obtain more accurate results. Additionally, regarding the mechanism of contraceptive hormones' effect on breast cancer, it was also hypothesized that a direct relationship between weight and estrogen levels with hormone consumption can indirectly increase the risk for developing breast cancer. ${ }^{61}$ Thus, further studies are needed to prove this hypothesis.

Initial and final analysis of multivariate regression indicated a relationship between history of hormone therapy and risk of breast cancer. Hormonal therapies increased risk for developing breast cancer. Based on the dose-response curve, there was a direct relationship between hormone therapy and incidence of breast cancer so that increased use of hormone elevated the risk for developing breast cancer. However, changes in these effects have not been completely recorded among different populations and ethnic groups. ${ }^{62}$ Keihanian et $\mathrm{al}^{63}$ found no significant relationship in this regard. Given that hormone therapy is prescribed by the specialist for certain reasons, and it differs depending on the type of compounds, further research is needed on the type of hormones, compounds, and duration of use.

In the current research, a positive family history of breast cancer in first-degree relatives was identified as a risk factor for breast cancer. This finding was consistent with the study by Devi et al. ${ }^{53}$ Regarding the role of biological and genetic markers in women with a positive family history of breast cancer in first-degree relatives, increasing their awareness about screening, early diagnosis, and timely treatment can help in reducing the death rate among this group of women.

There was also no significant relationship between history of chest radiotherapy, age of the first marriage, number of deliveries, history of abortion and risk for developing breast cancer. Nonetheless, more studies are required in this field of research.

\section{Strengths and Weaknesses}

Given the nature of case-control studies that may be subjected to limitations such as selection bias and recall bias, it was more probable that the case group remembered disease-related factors. Besides interviews carried out by the researchers, every attempt was made to use as much information as possible recorded in the patients' files. The control group was also followed up for 2 years. Subjects of the control group were also selected among those referred to the hospital, which can somehow minimize the possibility of selection bias and recall bias. Although other factors influencing breast cancer were not evaluated in this study, sensitivity and characteristics of the logistic model indicated adequacy of the model and studied variables. The inclusion of new patients diagnosed during 2013-2017 was considered as the strength of the study; however, it prolonged the study period.

\section{Conclusion}

With respect to the importance of fertility-related factors and the use of hormones in developing breast cancer, especially in developing countries, it is better to design a comprehensive plan to control risk factors that can be prevented; e.g. reducing age of marriage, promoting pregnancy and childbirth at an early age, reducing the use of hormones for various purposes, and educating and sensitizing the women. In addition, increasing awareness of women with a positive family history for breast cancer to perform regular tests and refer to the doctor for timely diagnosis and treatment can be effective in reducing the incidence rate of this disease.

\section{Acknowledgments}

The authors would like to thank the Clinical Research Development Unit (CRDU) of Emam Khomeini Hospital and Emam Reza Hospital, University of Medical Sciences, Kermanshah, Iran for their support, cooperation, and assistance throughout the period of study.

\section{Author Contributions}

Mehdi Moradinazar and Behjat Marzbani contributed substantially to the conception and design of the project. Mehdi Moradinazar and Behjat Marzbani were responsible for the acquisition of data and the analysis. All authors contributed to the interpretation of data. All 
authors contributed to drafting the article and revising it critically for important intellectual content. All authors have provided the final approval of the version to be published, and agree to be accountable for all aspects of the work.

\section{Funding}

This study was funded by Kermanshah University of Medical Sciences (Grant number: 980582).

\section{Disclosure}

Behjat Marzbani reports Kermanshah University of Medical Sciences has donated the research team in Executive stage of research, outside the submitted work. The authors declare that they have no other conflicts of interest. This project was approved and financed by the Vice Chancellor for Research and Research and Technology, Kermanshah University of Medical Sciences, Kermanshah, Iran (IR.KUMS. RES.1398.672).

\section{References}

1. Mahmoodian F, Shekarkhand N. Strategic training methods regarding the physicians and nurses' clinical relationships with the patients suffering from cancer. Sadra Med Sci J. 2017;2(1):102-189.

2. Cummings SR, Tice JA, Bauer S, et al. Prevention of breast cancer in postmenopausal women: approaches to estimating and reducing risk. J Natl Cancer Inst. 2009;101(6):384-398. doi:10.1093/jnci/djp018

3. Naghibi SSD, Yazdani CJ, Montazeri A. Breast cancer preventive behaviors among Iranian women: a systematic review. Payesh. 2015;14(2):181-191. Persian.

4. Torre LA, Bray F, Siegel RL, Ferlay J, Lortet-Tieulent J, Jemal A. Global cancer statistics, 2012. CA Cancer J Clin. 2015;65(2):87-108. doi: $10.3322 /$ caac. 21262

5. Roohparvarzade N. Prevalence of risk factors for breast cancer in women (20 to 69 years old) in Isfahan 2012-2013. Iran $Q J$ Breast Dis. 2014;7(1):52-61.

6. Ferlay JSH, Bray F, Forman D, Mathers C, Parkin D. GLOBOCAN 2008 V1. 2, Cancer Incidence and Mortality Worldwide: IARC CancerBase No. 10 [Internet]. Lyon, France: International Agency for Research on Cancer; 2010.

7. DeSantis CSRBP, Jemal A. Global cancer statistics. CA. 2011;61 (6):408-418

8. Dong J-Y, Zhang L, He K, Qin L-Q. Dairy consumption and risk of breast cancer: a meta-analysis of prospective cohort studies. Breast Cancer Res Treat. 2011;127(1):23-31. doi:10.1007/s10549-011-1467-5

9. Kojima R, Okada E, Ukawa S, et al. Dietary patterns and breast cancer risk in a prospective Japanese study. Breast Cancer. 2017;24 (1):152-160. doi:10.1007/s12282-016-0689-0

10. Walker R, Lees E, Webb M, Dearing S. Breast carcinomas occurring in young women (<35 years) are different. Br J Cancer. 1996;74(11):1796.

11. Albain KS, Allred DC, Clark GM. Breast cancer outcome and predictors of outcome: are there age differentials?. J National Cancer Inst Monogr. 1994;16:35-42.

12. Pourfarzi F, Fouladi N, Amani F, Ahari SS, Roshani Z, Alimohammadi S. Factors affecting preferences of iranian women for breast cancer screening based on marketing mix components. Asian Pac J Cancer Prev. 2016;17(8):3939-3943.
13. Tazhibi M, Feizi A. Awareness levels about breast cancer risk factors, early warning signs, and screening and therapeutic approaches among Iranian adult women: a large population based study using latent class analysis. Biomed Res Int. 2014;2014:306352.

14. Statsenko M, Turkina S, Kosivtseva M. Additional advantages of mexicor used in combined therapy of coronary heat disease and diabetes mellitus of 2nd type. Klin Med (Mosk). 2013;91(5):59-64.

15. Tehranian N, Shobeiri F, Pour FH, Hagizadeh E. Risk factors for breast cancer in Iranian women aged less than 40 years. Asian Pacif J Cancer Prev. 2010;11(6):1723-1725.

16. Motie MR, Besharat S, Torkjazi R, et al. Modifiable risk of breast cancer in northeast Iran: hope for the future. A Case-Control Study. Breast Care. 2011;6(6):453-456. doi:10.1159/000335203

17. Mousavi SM, Montazeri A, Mohagheghi MA, et al. Breast cancer in Iran: an epidemiological review. Breast J. 2007;13(4):383-391. doi:10.1111/tbj.2007.13.issue-4

18. Ahmadian M, Samah AA. A literature review of factors influencing breast cancer screening in Asian countries. Life Sci J. 2012;9:585-594.

19. Kelsey JL, Berkowitz GS. Breast cancer epidemiology. Cancer Res. 1988;48(20):5615-5623.

20. Montero JC, Ocana A, Abad M, Ortiz-Ruiz MJ, Pandiella A, Esparís-Ogando A. Expression of Erk5 in early stage breast cancer and association with disease free survival identifies this kinase as a potential therapeutic target. PLoS One. 2009;4(5):e5565. doi:10.1371/journal.pone.0005565

21. Ewertz M, Mellemkjaer L, Poulsen A, et al. Hormone use for menopausal symptoms and risk of breast cancer. A Danish Cohort Study. Br J Cancer. 2005;92(7):1293.

22. Mosher WD, Jones J. Use of contraception in the United States: 1982-2008. Vital Health Stat Ser 23 Data National Surv Family Growth. 2010;(29):1-44.

23. Humans Iwgoteocrt OW, Iafro C. Combined Estrogen-Progestogen Contraceptives and Combined Estrogen-Progestogen Menopausal Therapy. World Health Organization; 2007.

24. Kahlenborn C, Modugno F, Potter DM, et al.. Oral contraceptive use as a risk factor for premenopausal breast cancer: a meta-analysis. Mayo Clin Proc.2006;81:1290-1302. doi:10.4065/81.10.1290

25. Sweeney C, Giuliano AR, Baumgartner KB, et al. Oral, injected and implanted contraceptives and breast cancer risk among US hispanic and non-hispanic white women. Int $J$ Cancer. 2007;121 (11):2517-2523. doi:10.1002/(ISSN)1097-0215

26. Poosari A, Promthet S, Kamsa-Ard S, Suwanrungruang K, Longkul J, Wiangnon S. Hormonal contraceptive use and breast cancer in Thai women. J Epidemiol. 2014;24(3):216-220. doi:10.2188/jea.JE20130121

27. Kelishadi R, Ardalan G, Gheiratmand R, et al. Association of physical activity and dietary behaviours in relation to the body mass index in a national sample of Iranian children and adolescents: CASPIAN Study. Bulletin of the World Health Organization. 2007;85:19-26.

28. Marzbani B, Nazari J, Najafi F, et al. Dietary patterns, nutrition, and risk of breast cancer: a case-control study in the west of Iran. Epidemiol Health. 2019;41.

29. Colleoni M, Rotmensz N, Robertson C, et al. Very young women ( $<35$ years) with operable breast cancer: features of disease at presentation. Ann Oncol. 2002;13(2):273-279. doi:10.1093/annonc/ mdf039

30. Adami H-O, Malker B, Holmberg L, Persson I, Stone B. The relation between survival and age at diagnosis in breast cancer. $N$ Engl J Med. 1986;315(9):559-563. doi:10.1056/NEJM198608283150906

31. Jayasinghe UW, Taylor R, Boyages J. Is age at diagnosis an independent prognostic factor for survival following breast cancer? ANZ J Surg. 2005;75(9):762-767. doi:10.1111/ans.2005.75.issue-9

32. Marzbani B, Taymoori P, Nouri B. Assessment of risk factors for breast cancer among women under 50 years old. $J$ School of Public Health Inst Public Health Res. 2017;15(1):47-60. 
33. Besharat S, Motie MR, Besharat M, Roshandel G. Breast cancer risk factors in women of Golestan Province in Iran: a case-control study. Iranian J Obstetrics Gynecol Infertility. 2011;13(6):46-51.

34. Sharifzadeh GR, Hosseini M, Kermani T, Ataie M, Akhbari S. Breast cancer and the related factors: a case control study. J Birjand Univ Med Sci. 2011;191-199.

35. Das S, Sen S, Mukherjee A, Chakraborty D, Mondal PK. Risk factors of breast cancer among women in eastern India: a tertiary hospital based case control study. Asian Pacif J Cancer Prev. 2012;13 (10):4979-4981. doi:10.7314/APJCP.2012.13.10.4979

36. Fraumeni JFSD. Cancer Epidemiology and Prevention. Oxford University Press; 2006.

37. Galukande M, Wabinga H, Mirembe F, Karamagi C, Asea A. Breast cancer risk factors among Ugandan women at a tertiary hospital: a case-control study. Oncology. 2016;90(6):356-362. doi:10.1159/ 000445379

38. Ebrahimi M, Vahdaninia M, Montazeri A. Risk factors for breast cancer in Iran: a case-control study. Breast Cancer Res. 2002;4(5): R10. doi:10.1186/bcr454

39. Motamed N, Hadi N, Talei A. A Survey on Risk Factors of Breast Cancer in Women Over 35 Years of Age (Shiraz-2000). Journal of Advances in Medical and Biomedical Research. 2004;12(46):25-32.

40. Thongsuksai P, Chongsuvivatwong V, Sriplung H. Delay in breast cancer care: a study in Thai women. Med Care. 2000;38(1):108-114. doi:10.1097/00005650-200001000-00012

41. Alim NE, Kiziltan G. Assessment of risk factors of obesity and diet on breast cancer in Ankara, Turkey. Pak J Med Sci. 2016;32(6):1537.

42. Protani M, Coory M, Martin JH. Effect of obesity on survival of women with breast cancer: systematic review and meta-analysis. Breast Cancer Res Treat. 2010;123(3):627-635. doi:10.1007/s105 s49-010-0990-0

43. Goodwin PJ, Stambolic V. Impact of the obesity epidemic on cancer. Annu Rev Med. 2015;66:281-296. doi:10.1146/annurev-med-051613012328

44. Hsieh CC, Trichopoulos D, Katsouyanni K, Yuasa S. Age at menarche, age at menopause, height and obesity as risk factors for breast cancer: associations and interactions in an international casecontrol study. Int J Cancer. 1990;46(5):796-800. doi:10.1002/ ijc. 2910460508

45. Hajifoghaha M, Mirmiran P, Alizadeh S. Modification of food consumption, reduction of breast cancer: a review study. 2016;12 (3):683-691. doi:10.1177/1753193416641319

46. Verloop J, Rookus MA, van der Kooy K, van Leeuwen FE. Physical activity and breast cancer risk in women aged 20-54 years. J Natl Cancer Inst. 2000;92(2):128-135. doi:10.1093/jnci/92.2.128

47. Autier P, Boffetta P, Boniol M, Boyle P, Ferlay J, Aurengo A. Attributable Causes of Cancer in France in the Year 2000. Lyon: IARC; 2007:172.

48. Pizot C, Boniol M, sMullie P, et al. Physical activity, hormone replacement therapy and breast cancer risk: a meta-analysis of prospective studies. Eur J Cancer. 2016;52:138-154. doi:10.1016/j. ejca.2015.10.063
49. Cancer CGoHFiB. Menarche, menopause, and breast cancer risk: individual participant meta-analysis, including 118964 women with breast cancer from 117 epidemiological studies. Lancet Oncol. 2012;13(11):1141-1151. doi:10.1016/S1470-2045(12)70425-4

50. Jafarinia B, Bahadorzai M, Delpisheh A, Sayehmiri K, Tavakoli M. Risk factors of breast cancer in Dezful city of Iran: a case-control study. Tehran Univ Med J TUMS Publ. 2016;74(2):135-139.

51. Toleutay U, Reznik V, Kalmatayeva Z, Smigelskas K. Risk factors of breast cancer in Kyzylorda oblast of Kazakhstan: a case-control study. Asian Pacif J Cancer Prev. 2013;14(10):5961-5964. doi:10.7314/APJCP.2013.14.10.5961

52. Kamath R, Mahajan KS, Ashok L, Sanal T. A study on risk factors of breast cancer among patients attending the tertiary care hospital, in udupi district. Indian J Community Med. 2013;38(2):95. doi:10.4103/ 0970-0218.112440

53. Devi BN, BabuRao B, K. AK. A case control study on risk factors of breast cancer among women attending MNJ Cancer Hospital, Hyderabad. Int J Biomed Adv Res. 2016;7(2):79-82. doi:10.7439/ ijbar.v7i2.2993

54. Peck JD, Hulka BS, Poole C, Savitz DA, Baird D, Richardson BE. Steroid hormone levels during pregnancy and incidence of maternal breast cancer. Cancer Epidemiol Prev Biomarkers. 2002;11 (4):361-368.

55. Russo J, Tay LK, Russo IH. Differentiation of the mammary gland and susceptibility to carcinogenesis. Breast Cancer Res Treat. 1982;2 (1):5-73.

56. Kauppila A, Kyyrönen P, Lehtinen M, Pukkala E. Dual effect of short interval between first and second birth on ductal breast cancer risk in Finland. Cancer Causes Control. 2012;23(1):187-193. doi:10.1007/ s10552-011-9868-7

57. Tryggvadóttir L, Tulinius $\mathrm{H}$, Eyfjord JE, Sigurvinsson $\mathrm{T}$. Breastfeeding and reduced risk of breast cancer in an Icelandic cohort study. Am J Epidemiol. 2001;154(1):37-42. doi:10.1093/aje/154.1.37

58. Harrison PA, Srinivasan K, Binu V, Vidyasagar M, Nair S. Risk factors for breast cancer among women attending a tertiary care hospital in southern India. Int $J$ Collab Res Internal Med Public Health. 2010;4:109-116

59. Heimdal K, Skovlund E, Møller P. Oral contraceptives and risk of familial breast cancer. Cancer Detect Prev. 2002;26(1):23-27. doi:10.1016/S0361-090X(02)00004-1

60. Strom BL, Berlin JA, Weber AL, et al. Absence of an effect of injectable and implantable progestin-only contraceptives on subsequent risk of breast cancer. Contraception. 2004;69(5):353-360. doi:10.1016/j.contraception.2003.12.015

61. Cleary MP, Grossmann ME. Obesity and breast cancer: the estrogen connection. Endocrinology. 2009;150(6):2537-2542. doi:10.1210/ en.2009-0070

62. Amadou A, Fabre A, Torres-Mejía G, et al. Hormonal therapy and risk of breast cancer in Mexican women. PLoS One. 2013;8(11): e79695. doi:10.1371/journal.pone.0079695

63. Keihanian S, Ghaffari F, Fotokian Z, Shoormig R, Saravi M. Risk factors of breast cancer in Ramsar and Tonekabon. J Qazvin Univ Med Sci. 2010;14(2):12-19.

\section{Publish your work in this journal}

Breast Cancer - Targets and Therapy is an international, peer-reviewed open access journal focusing on breast cancer research, identification of therapeutic targets and the optimal use of preventative and integrated treatment interventions to achieve improved outcomes, enhanced survival and quality of life for the cancer patient.
The manuscript management system is completely online and includes a very quick and fair peer-review system, which is all easy to use. Visit http://www.dovepress.com/testimonials.php to read real quotes from published authors. 